Интернет-журнал «Науковедение» ISSN 2223-5167 http://naukovedenie.ru/

Том 8, №6 (2016) http://naukovedenie.ru/vol8-6.php

URL статьи: http://naukovedenie.ru/PDF/60EVN616.pdf

DOI: 10.15862/60EVN616 (http://dx.doi.org/10.15862/60EVN616)

Статья опубликована 05.12.2016

Ссылка для цитирования этой статьи:

Бублик Н.Д., Лукина И.И., Фазлутдинов Р.А., Чувилин Д.В. Предпосылки формирования концепции сбалансированных инициатив на основе адаптации партисипаторного бюджетирования к условиям России // Интернет-журнал «НАУКОВЕДЕНИЕ» Том 8, №6 (2016) http://naukovedenie.ru/PDF/60EVN616.pdf (доступ свободный). Загл. с экрана. Яз. рус., англ. DOI: 10.15862/60EVN616

\title{
УДК 336.14
}

Бублик Николай Дмитриевич

ФГОБУ ВО «Финансовый университет при Правительстве Российской Федерации» Филиал в г. Уфа, Россия, Уфа ${ }^{1}$

Профессор кафедры «Экономика, менеджмент и маркетинг» Доктор экономических наук

E-mail: Bnd-ufa@bk.ru

Лукина Ирина Ивановна

ФГОБУ ВО «Финансовый университет при Правительстве Российской Федерации» Филиал в г. Уфа, Россия, Уфа

Доцент кафедры «Финансы и кредит» Кандидат экономических наук

E-mail: Irina-ufa@bk.ru

\section{Фазлутдинов Рустам Анфирович}

Аппарат Правительства Республики Башкортостан, Россия, Уфа Директор департамента управления финансовыми, имущественными и контрактными отношениями E-mail: Fazlutdinov.r@bashkortostan.ru

\section{Чувилин Денис Валерьевич}

ФГОБУ ВО «Финансовый университет при Правительстве Российской Федерации» Филиал в г. Уфа, Россия, Уфа

Доцент кафедры «Финансы и кредит» Кандидат экономических наук E-mail: DVChuvilin@fa.ru

\section{Предпосылки формирования концепции сбалансированных инициатив на основе адаптации партисипаторного бюджетирования к условиям России}

Аннотация. В статье изложены результаты исследования мировой и отечественной практики партисипаторного бюджетирования, проведенных на основе систематизации публикаций отечественных и зарубежных ученых и практиков. Выявлено, что основная часть исследований посвящена социально-политической составляющей процессов партисипаторного бюджетирования. В тоже время отмечается, что за 25 лет использования 
партисипаторного бюджетирования сформировалось несколько тенденций, включая: увеличение масштабов, рост многообразия форм и механизмов; присутствие противоречивых факторов, приводящих к появлению негативных эффектов и недовольству результатами совместной работы в среднесрочной перспективе.

В работе выдвинута гипотеза о зависимости развития партисипаторного бюджетирования от уровня знаний и компетенций населения. На основе анализа статистических данных по 40 странам выявлена прямая зависимость между уровнем образования и масштабами партисипаторного бюджетирования. В этой связи обосновывается необходимость формирования отечественной модели партисипаторного бюджетирования. Однако в настоящее время отечественные практики партисипаторного бюджетирования во многом опираются на мировой опыт. Существует перекос в сторону поддержки местных инициатив для решений острых, но единичных проблем сообществ.

В статье предложен авторских подход к определению места партисипаторного бюджетирования в системе гражданской активности на основе четырех перспектив сбалансированной системы показателей (ССП). Определено, что партисипаторное бюджетирование как элемент финансовой перспективы характеризует итоговые результаты общественных процессов, связанных с формированием стоимостных оценок и пропорций. Таким образом, предполагается, что эффективность партисипаторного бюджетирования во многом определяется уровнем развития других форм самоорганизации. В этой связи предложена эволюционная «спираль» демонстрирующая логику формирования эффектов синергии и последовательность развития форм общественной самоорганизации.

Для разработки отечественной модели партисипаторного бюджетирования в рамках выдвинутой концепции сбалансированных инициатив сформулированы принципиальные аспекты, учитывающие специфику российских условий: отказ от социально-политических оценок в пользу комплексной оценки на основе ценностно ориентированного подхода; использование механизмов сбалансированной системы показателей для выбора лучших вариантов инициатив; переход от экспертно-эвристических механизмов бюджетирования к механизмам на основе количественного моделирования социально-экономических параметров. Определены элементы концепции сбалансированных инициатив и основные этапы ее реализации в Республике Башкортостан.

Ключевые слова: партисипаторное бюджетирование; инициативное бюджетирование; бюджет развития; местные сообщества; сбалансированный инициативы; сбалансированная система показателей (ССП); процедуры бюджетирования; распределение бюджета; муниципальные инвестиции; проекты развития

\section{Актуальность партисипаторного бюджетирования в условиях развития самоорганизации}

В настоящее время в условиях усложнения и повышения динамизма экономики явление самоорганизации граждан становится все более заметным и значимым фактором развития во многих сферах общественной жизнедеятельности. Институты гражданского общества играют все более заметную роль в принятии социально значимых решений и контроле их исполнения. Деятельность Общественной палаты, общественных советов и центров общественного контроля на федеральном, региональном и местном уровне позволяет инициировать и организовывать гражданскую активность в созидательном русле. По оценкам сопредседателя Центрального штаба Общероссийского народного фронта Александра Бречалова в 2015 году в общественную деятельность в России было вовлечено на постоянной основе около $1 \%$ активного населения, что составляет примерно 1 млн. человек. Для 
сравнения в странах Западной Европы аналогичный показатель составляет до 10\% от экономически активного населения.

В 2014-2015 годах в стране сложились уникальные условия для повышения уровня консолидации гражданского общества, одним из проявлений которых стало патриотическое движение «Бессмертный полк», организованное в канун празднования 75-летия Победы в Великой отечественной войне и объединившее 9 мая 2015 года 12 млн. человек по всей стране. Этот факт является признаком того, что граждане страны при определенных условиях, ясных целях и соответствующих ресурсных возможностях способны мобилизоваться для реализации своей гражданской позиции и активности в различных формах. Особый интерес на данном этапе развития экономики России представляет возможность практического использования этого фактора в рамках общественной самоорганизации, что по существу может быть основой для организации и применения нового нематериального актива.

В этой связи своевременными и актуальными стали исследования Научноисследовательского финансового института (НИФИ) и Европейского университета в СанктПетербурге, посвященные инициативному и партисипаторному бюджетированию, результаты которых отражены в целом ряде публикаций в России и за рубежом. Несмотря на то, что партисипаторное бюджетирование известно в мире с 1989 года, это относительно новая для условий России форма проявления самоорганизации граждан, которая может стать важным элементом повышения эффективности использования финансовых ресурсов бюджетов муниципальных образований.

Организация энергоснабжения, обслуживание общественно значимой инфраструктуры, содержание дорог, переселение из ветхого и аварийного жилья, поддержка малоимущих граждан - вот основные проблемы муниципальных образований, требующие финансовых ресурсов. Особенно остро эти проблемы стоят в сельских муниципальных образованиях, где дотационность достигает до 90\%.

Одним из направлений повышения эффективности управления муниципалитетом является поэтапное включение населения в процесс разработки и принятия общественно значимых решений - от управления многоквартирными домами до формирования генерального плана развития муниципального образования. Особый интерес представляет разработка и внедрение процессной модели управления инициативами муниципального развития, цель которой - установить в условиях дефицита бюджетных средств взаимосвязи и сотрудничество местной власти, населения и бизнеса в рамках региональных и муниципальных программ социально-экономического развития.

\section{Систематизация и критика партисипаторного бюджетирования в зарубежных исследованиях}

Проведенная в исследованиях НИФИ и Европейского университета в СанктПетербурге за последние годы систематизация зарубежной и отечественной практики партисипаторного бюджетирования позволила определить его масштабы, темпы роста и разнообразие форм проявлений $[7,8,9]$.

Безусловно, зарубежный опыт, теоретические основы и анализ партисипаторного бюджетирования в настоящее время являются более богатыми и значимыми, чем отечественное видение. В этой связи обращают на себя внимания исследования И. Сентомер, К. Херцберг, А. Рёке и Дж. Аллегретти, в которых изложены результаты периодического мониторинга масштабов и показателей развития партисипаторного бюджетирования в мире, его осмысление и систематизация. Так по их данным, в 2012 году реализовывалось более 2000 проектов партисипаторного бюджетирования. При этом по разным данным более половины всех проектов приходилось на Польшу, Бразилию, Перу [11, с. 14]. Однако, несмотря на 
достаточно скрупулёзный и многоплановый анализ мирового опыта, проведенный авторами указанного исследования, обращает на себя внимание отсутствие попыток установления взаимосвязей и закономерностей между уровнем развития партисипаторного бюджетирования и параметрами социально-экономического развития соответствующих стран.

Систематизация содержания партисипаторного бюджетирования впечатляюще емко проведена в работе [11, с. 16], в результате чего выделено шесть концептуальных моделей, включая: партисипаторная демократия; демократия сближения; партисипаторная модернизация; мульти-стейкхолдерское участие; нео-корпоративизм; развитие сообщества.

В основу предложенной классификации положено несколько признаков, включая: контекст; нормативные ограничения и цели; процедуры; содержание коллективного действия; связь между традиционным и партисипаторным политическим процессом; преимущества и недостатки; страны преимущественного использования.

Нетрудно заметить, что представленная классификация в большой степени ориентирована на социально-политическую составляющую процесса партисипаторного бюджетирования. Кстати такой подход к рассмотрению партисипаторного бюджетирования как, прежде всего, инструмента «народной демократии» является преобладающим в зарубежных публикациях.

В настоящее время имеется ряд аналитических публикаций, посвященных критическому и комплексному анализу проблем использования партисипаторного бюджетирования, выявленных за 25 лет его применения. Так, например, можно выделить три ключевых позиции критики проектов партисипаторного бюджетирования в Германии [12]:

1) исходные цели вовлечения граждан в сложный и многосторонний процесс формирования муниципального бюджета не достигаются. В настоящее время часто это становится только сбором предложений по мерам и проектам или процедурами голосования по предложениям, внесенным политиками и администраторами, которые работают под известным брендом «партисипаторного бюджетирования»;

2) низкое число участвующих граждан и неравномерность представления различных половозрастных групп. Это приводит к превалированию влиянию отдельных лиц или групп, отстаивающих те или иные интересы и соответственно политически мотивированных. В результате эти участники партисипаторного бюджетирования получают дополнительные возможности в принятии решений;

3) слабая устойчивость гражданского участия. Многие из реализованных проектов партисипаторного бюджетирования показывают трудности в их продолжении в течение длительного периода времени. Они либо прекращаются совсем, либо от них остаются только зачатки первоначально амбициозных идеи.

Во многом схожие недостатки отмечаются в практике реализации совместного бюджетирования в Перу [10]:

- недостаточно репрезентативный и диверсифицированный состав участников, в частности это связано с половозрастным составом, Кроме того присутствует некий неформальный денежный ценз, связанный с затратами участия в партисипаторном бюджетировании. Такие затраты могут связаны с проездом, питанием, проживанием, потерей времени и т.д. Всемирный банк подсчитал, что возможные затраты для перуанского сельского жителя, участвующего в бюджетном процессе в течение года, могут достигать 195 долл. США или 95\% минимальной месячной оплаты труда;

- $\quad$ сомнения в улучшении использования государственных расходов. Большинство проектов, поддерживаемых в рамках партисипаторного бюджетирования, являются «социальными», то есть ориентированы на бедные слои и решение самых острых и 
актуальных проблем. Трудно оценить долгосрочный эффект от таких проектов. Кроме этого, как правило, наблюдается рост масштабов реализуемых проектов. При этом часто возникают сложности с реализацией выбранных проектов. Так, по оценке Всемирного банка, до 50\% отобранных проектов не выполняются по техническим, политическим и другим причинам. Это в свою очередь приводит к потере доверия к процессу со сторону участников;

- $\quad$ рост нестабильности, связанной с увеличением числа конфликтов на субнациональном уровне. По оценкам некоторых ученых, на этот процесс в том числе повлияли реформы национального законодательства по партисипаторному бюджетированию. Жители Перу стали прибегать к коллективным действиям в связи с возрастающими жалобами на горнодобывающие компании, программы развития частного сектора, министерства, депутатов и т.д.;

- неизменное восприятие реформ и мер местных органов власти. Проведенное социологическое исследование показало, что в период с 2001 по 2010 года практически не изменился процент доверия местным правительствам. Более того, доля опрошенных, принимавших участие в различных городских собраниях, с 1998 по 2012 год сократилась с $21 \%$ до $12 \%$.

Таким образом, анализ зарубежной практики партисипаторного бюджетирования показывает наличие нескольких тенденций:

1. Увеличение масштабов партисипаторного бюджетирования как общемировая тенденция, в том числе связанная с общим ростом уровня образования.

2. Рост многообразия форм и механизмов партисипаторного бюджетирования, требующих осмысления и систематизации в различных аспектах.

3. Наличие ряда противоречивых факторов, приводящих не только к снижению эффективности партисипаторного бюджетирования, но и к появлению «обратных» эффектов, связанных с недовольством населения итоговыми результатами совместной работы.

\section{Особенности партисипаторного бюджетирования в условиях России}

Не преследуя цель выявить всю совокупность наиболее значимых для развития партисипаторного бюджетирования факторов, а скорее для активизации этого направления исследований авторами данной работы был проведен предварительный статистический анализ зависимости между количеством реализуемых проектов и уровнем образования населения в соответствующих странах. То есть выдвинута гипотеза о том, что для успешной реализации функций самоорганизации в процессе составления и использования местных бюджетов важнейшим фактором является уровень знаний и компетенций населения. Для проверки данной гипотезы был использован показатель процента охвата высшим образованием (Gross enrolment ratio, tertiary, both sexes), представленный в базах данных Всемирного банка и базы данных $\mathrm{OOH}$.

Проведенные вычисления средствами Excel показали, что для всей совокупности рассматриваемых стран (всего 40 стран за исключением стоящих особняком Польши, Бразилии и Перу) наблюдается относительно слабая прямая зависимость между рассматриваемыми параметрами. Однако разделение той же совокупности стран на две группы с уровнем охвата высшим образованием соответственно менее и более 50\%, позволило более явно выявить эту зависимость (см. рис. 1). 

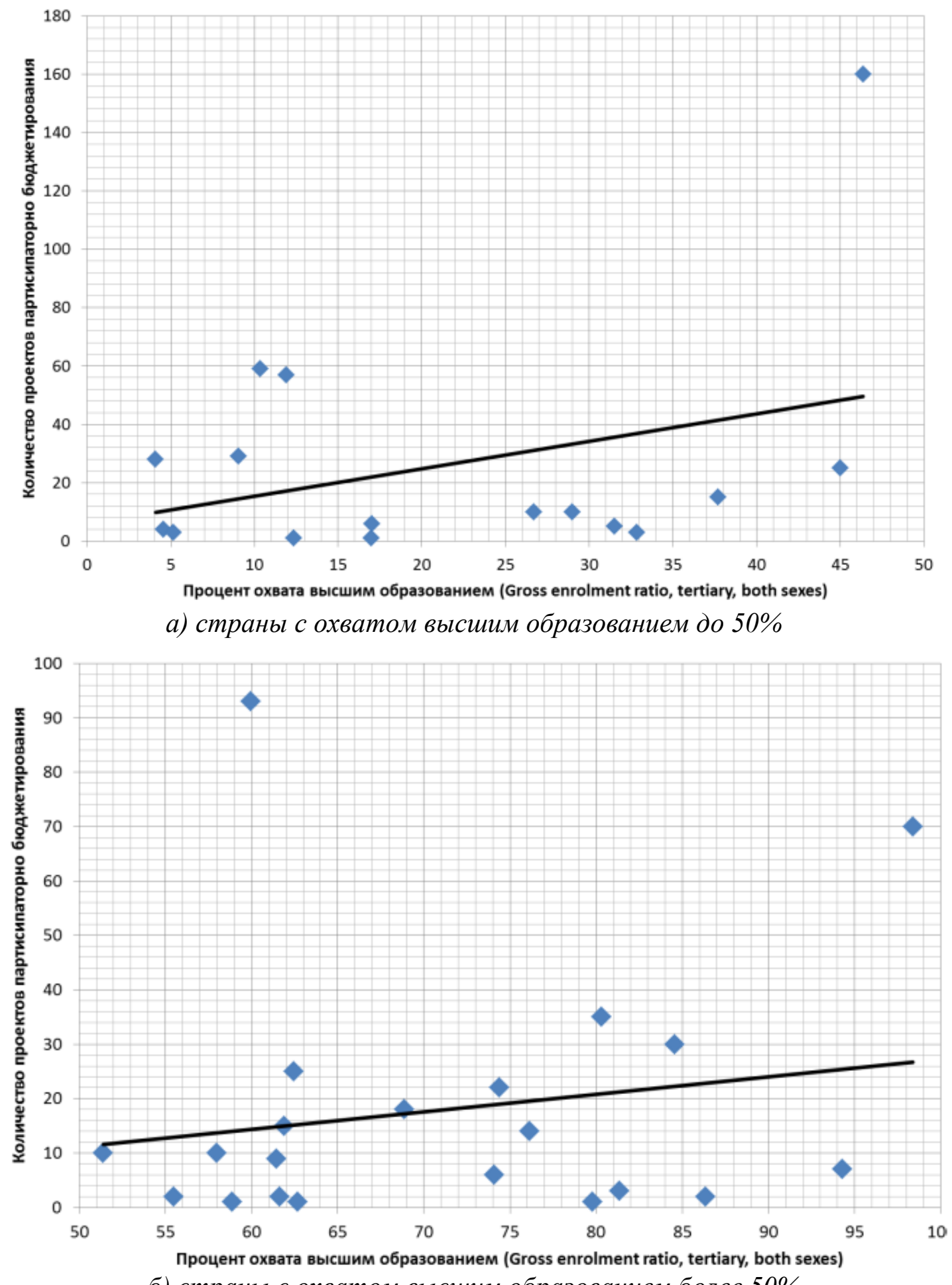

б) страны с охватом высшим образованием более $50 \%$

Рисунок 1. Зависимость между числом проектов партисипаторного бюджетирования и уровнем образования населения (разработано авторами)

В целом полученные результаты свидетельствуют о наличии прямой зависимости между ростом уровня образованности населения и масштабами партисипаторного бюджетирования. Причем для первой группы стран данная зависимость более выражена, чем для второй. Россия находится в числе стран с наиболее высоким уровнем охвата высшим образованием вместе с Чили, Новой Зеландией, Аргентиной, Исландией, Испанией, Австралией, США и Южной Кореей. При этом по количеству проектов партисипаторного 
бюджетирования Россия отстает только от четырех стран из этой группы: Чили, Аргентина, Испания, Южная Корея.

С позиции проведенного анализа количества проектов в зависимости от уровня образования можно предположить, что может быть продуктивен и анализ их содержания, в частности - уровень финансовой грамотности, показатели социального партнерства органов местного самоуправления и населения, эффективность принимаемых решений в условиях нестабильной рыночной среды. В этом смысле наиболее полезным, как нам представляется, является опыт Южной Кореи, которая характеризуется как высокой активностью граждан (70 проектов), так и близким к максимальному охвату высшим образованием населения.

В контексте полученных результатов можно предположить, что подобный анализ в дальнейшем может быть дополнен рассмотрением таких показателей, как уровень ВВП на душу населения, уровень безработицы и т.д.

В российских условиях в отличие от зарубежных практик, как было показано нами в предыдущих публикациях [1], преобладающим может стать организационно-экономический аспект, рассматривающий партисипаторное бюджетирование как форму самоорганизации с позиции взаимодействия граждан и как нематериальный актив, ориентированный на повышение эффективности использования ресурсов местных сообществ, включая финансовые ресурсы, землю, имущество и проч. С этой точки зрения зарубежные исследования могут быть существенно пересмотрены и дополнены.

Следует отметить, что для российской практики партисипаторного бюджетирования подобные комплексные исследования в настоящее время практически отсутствуют. В публикациях приводится содержание отдельных видов практики, однако требуется обобщающий анализ, который бы позволил четко определить ключевые признаки и факторы, обеспечивающие успешное применение партисипаторного бюджетирования. Наиболее полно и систематизировано процессы партисипаторного бюджетирования в России исследованы и обобщены в работах сотрудников НИФИ и Европейского университета в Санкт-Петербурге.

Содержание проектов партисипаторного бюджетирования, реализуемых в России Европейским университетом в Санкт-Петербурге, связано с участием горожан в распределении части средств муниципального бюджета посредством участия в специально создаваемых бюджетных комиссиях и рабочих группах [8]. Подобная схема взаимодействия населения и органов местного самоуправления ориентирована на повышение открытости принимаемых решений, обеспечение обратной связи с жителями, что в конечном итоге должно повысить эффективность муниципального управления.

Процесс партисипаторного бюджетирования предполагает целый набор процедур взаимодействия и выработки совместных решений, включая обсуждение муниципального бюджета; участие в проектировании и подаче бюджетных заявок; проведение регулярных собраний и специальных форумов и семинаров; подведение итогов и подготовка отчетов о расходовании бюджетных средств [8].

При этом процедуры партисипаторного бюджетирования, как правило, встраиваются в существующий бюджетный процесс. Гражданский инициативы, вырабатываемые в рамках бюджетных комиссий и рабочих групп, обсуждаются, учитываются при подготовке бюджетных заявок профильными комитетами органов местного самоуправления и в конечном итоге находят отражение в проекте городского бюджета.

Опыт реализации проектов партисипаторного бюджетирования позволил сотрудникам исследовательского центра «Res Publica» Европейского университета в Санкт-Петербурге сформулировать следующие преимущества создания бюджетных комиссий: 
1) реализация просветительской и образовательной функции партисипаторного бюджетирования;

2) выстраивание конструктивного диалога при рассмотрении актуальных вопросов муниципального хозяйства;

3) повышение ответственности граждан при формулировании инициатив, их обосновании и исполнении;

4) создание дополнительного мощного ресурса в генерировании свежих, часто нестандартных и высоко эффективных идей развития муниципалитета;

5) формирование нового слоя активной части горожан, опыт которых может быть использован в органах местного самоуправления.

В то же время выделяется ряд задач, которые предстоит решить в ходе развития практики партисипаторного бюджетирования в России, в том числе окончательное сближение партисипаторного бюджетирования и отечественного бюджетного и муниципального законодательства; формирование методических основ, обеспечивающих устойчивое использование партисипаторного бюджетирования, выдвижение и реализацию гражданских инициатив; повышение эффективности, усиление и углубление взаимодействия администраций и жителей муниципальных образований.

Несмотря на то, что отечественные практики партисипаторного бюджетирования во многом опираются на мировой опыт, используемые процедуры не всегда являются комплексными, законченными и, как следствие, эффективными. Наблюдается значительный перекос в сторону поддержки местных инициатив по решению наиболее острых, но единичных вопросов местного значения с привлечением софинансирования за счет средств граждан и местного бизнеса $[4,9]$. По мнению специалистов, фрагментарное использование возможностей партисипаторного бюджетирования не позволяет получить долгосрочный эффект активизации гражданских инициатив. Кроме этого отмечается недостаточное федеральное участие, слабость институциональной, организационной и информационной поддержки [7].

Анализ отечественной практики внедрения партисипаторного бюджетирования позволил также выявить ряд аспектов, которые сдерживают развитие и применение потенциала самоорганизации населения на муниципальном уровне:

- $\quad$ недооценка конструктивного потенциала общественной самоорганизации в органах местного самоуправления;

- незнание азов проектного управления работниками администраций муниципальных образований;

- $\quad$ недостаточные навыки общения чиновников и населения в режиме совместной выработки решений на местном уровне;

- н недоверие населения к «очередным» инновациям;

- $\quad$ отсутствие опыта у большинства граждан реального участия в публичных мероприятиях;

- отсутствие системы управления социально-экономическими рисками в муниципальных образованиях. 


\section{Предлагаемый подход и концепция развития партисипаторного бюджетирования в Республике Башкортостан}

Следует отметить, что существует огромное число инициируемых на местном уровне сфер применения, способов и возможностей проявления гражданской активности, каждая из которых может характеризоваться индивидуальными особенностями развития общественной и социально-экономической самоорганизации. Для их предварительной систематизации и анализа можно воспользоваться прошедшими апробацию в мировой практике стратегического управления четырьмя перспективами сбалансированной системь показателей (ССП), предложенными Нортоном и Капланом (см. рис. 2).

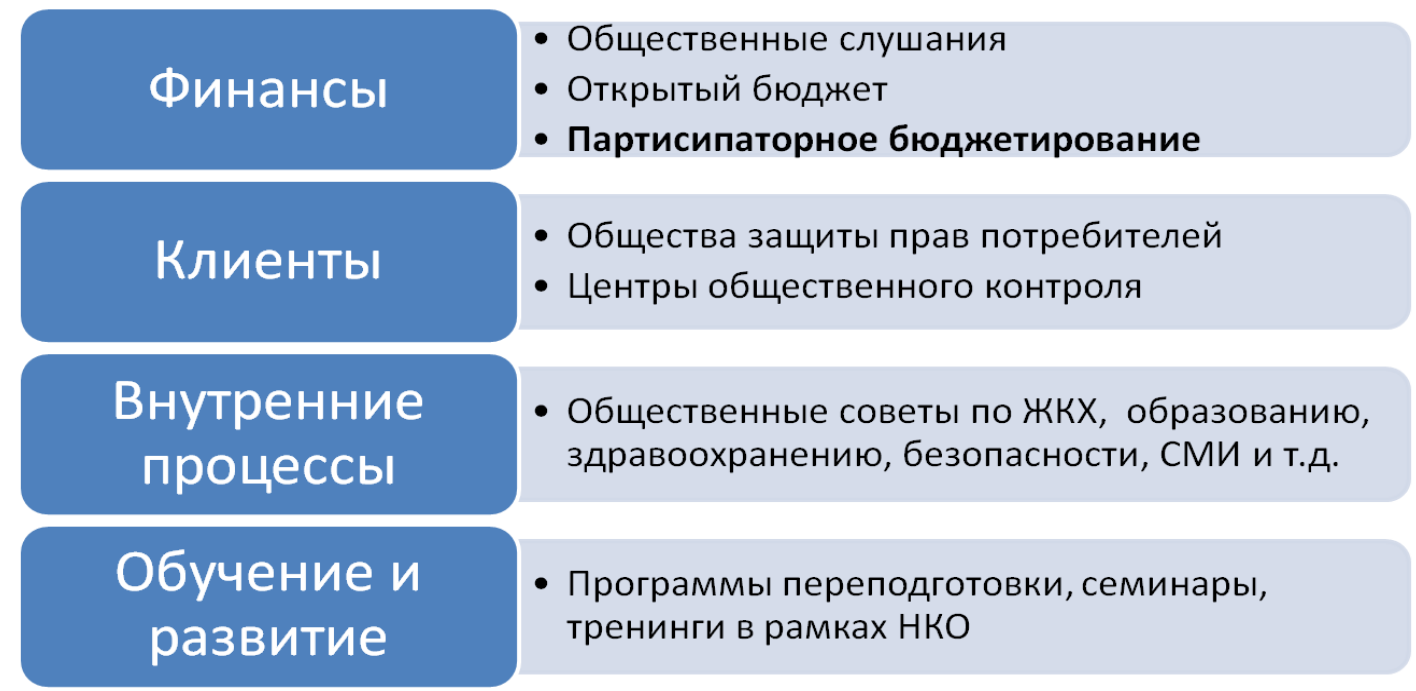

Рисунок 2. Некоторые формы самоорганизации в разрезе «перспектив» ССП муниципального образования (разработано авторами)

Представленная на рисунке 2 укрупненная систематизация не претендует на всеобъемлющий характер, однако позволяет в первом приближении классифицировать широкий спектр форм общественной самоорганизации в муниципалитетах. Кроме того, она позволяет отразить определенную логику упорядочения вариантов гражданской активности, которая в общем случае имеет направление движения «снизу-вверх», а именно:

1. Формирование человеческого потенциала на основе получения и использования новых знаний и компетенций в рамках перспективы «Обучение и развитие».

2. Активизация механизмов реализации имеющихся ресурсов на основе накопленного человеческого потенциала в рамках функционировании отдельных производственных подсистем по формированию ценности конечного общественного «продукта» (перспектива «Внутренние процессы»).

3. Оценка и контроль удовлетворенности существующих и перспективных общественных потребностей в рамках клиентской составляющей.

4. «Монетизация» итоговых результатов общественных процессов муниципалитета на основе формирования стоимостных оценок и определения стоимостных пропорций при составлении и исполнении бюджета (перспектива «Финансы»).

Естественно, что в представленной выше последовательности этапов наличествуют обратные связи и в целом данный процесс носит итеративный характер, так как совершенство и уровень развития форм самоорганизации «нижних перспектив» формируют условия и требования для развития самоорганизации на более высоком уровне (см. рис. 3). 


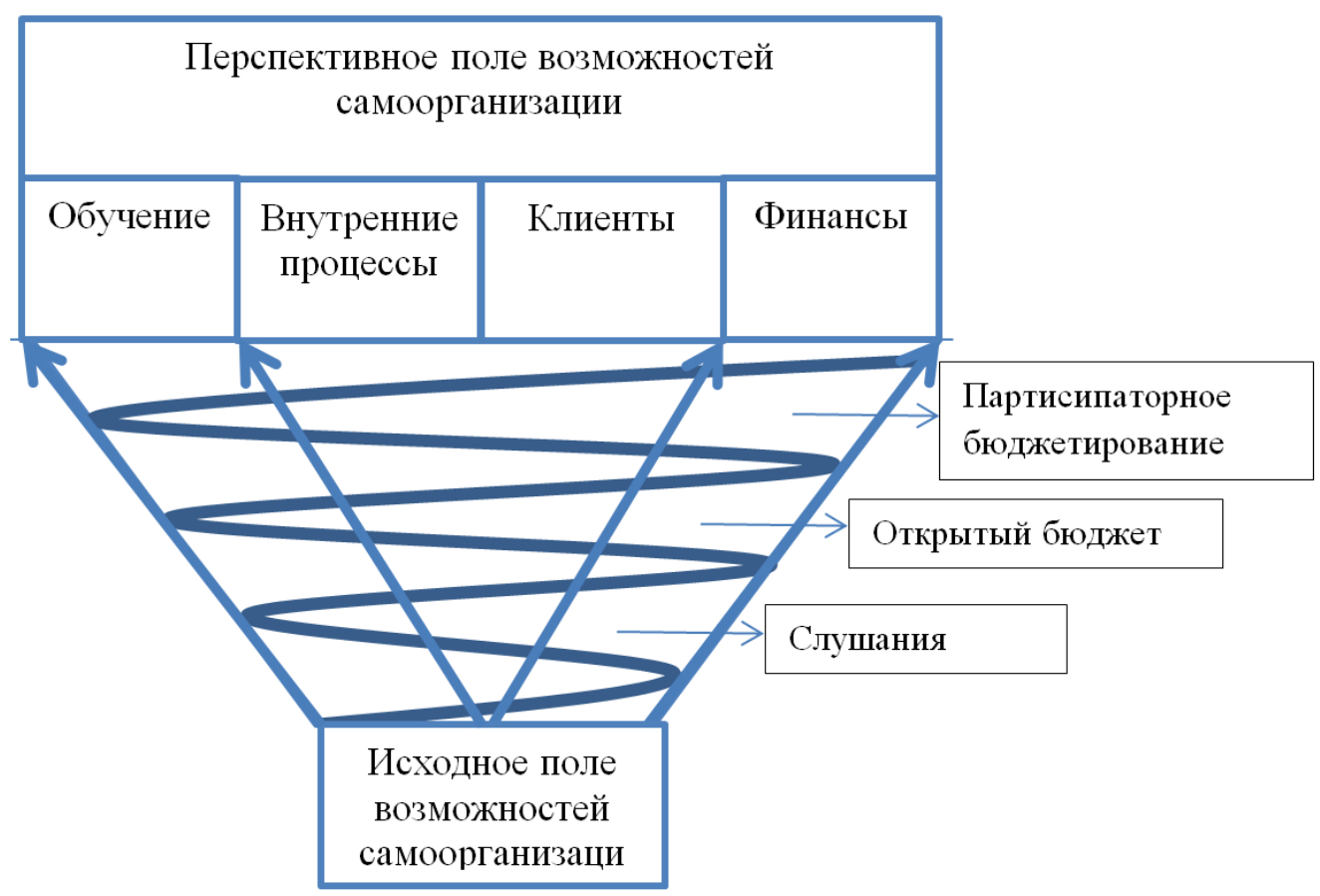

Рисунок 3. Эволючионная «спираль» развития форм самоорганизаџии в РФ в разрезе финансовой перспективы ССП (разработано авторами)

Показанная на рисунке 3 схема позволяет продемонстрировать логику формирования эффектов синергии и последовательность эволюции форм самоорганизации граждан в рамках изложенной выше классификации (см. рис. 2). В частности, нас интересует логика развития форм самоорганизации и влияние их на финансовую сферу муниципалитетов.

В начале 2000-х годов в практику бюджетного процесса на уровне регионов было введено понятие публичных слушаний по проекту бюджета и отчету по годовому исполнению бюджета. Затем появилось понятие «открытость бюджета», которое в начале (2006 г.) понималось с позиции прозрачности или понятности для граждан и популяризации бюджетной информации [6]. Сегодня тема «открытого бюджета» превратилась не просто в форму повышения информированности граждан, но и в «государственную политику, направленную на формирование доступной для понимания гражданами информации о бюджетах разного уровня, а также идеологию представителей государственной и местной власти по вовлечению граждан в процесс формирования доходной части бюджета и определения приоритетных направлений расходования бюджетных средств» [3]. Сегодня Российская Федерация является одной из ведущих стран по рейтингу открытости бюджетной системы, занимая 11-е место в мире [5]. Однако резкий рост за последние годы нефинансовых форм гражданской активности, получивших поддержку в связи с «майскими Указами» Президента в 2012 году, привел к пониманию недостаточности существующих механизмов «открытого бюджета» с позиции повышения эффективности использования возможностей самоорганизации.

Для успешной реализации партисипаторного бюджетирования в рамках расширения поля возможностей самоорганизации авторами предлагается сформулировать комплексную концепцию выдвижения и имплементации сбалансированных социальных инициатив. Концепция сбалансированных инициатив представляет собой авторскую трактовку содержания процесса партисипаторного бюджетирования применительно к отечественным условиям, учитывающего три аспекта упорядочения вариантов принимаемых решений [2]: 
- отказ от преимущественно социально-политических оценок в пользу комплексной оценки инициатив на основе ценностно-ориентированного подхода;

- использование механизмов ССП для выбора лучших вариантов решения социально-экономических проблем;

- переход от экспертно-эвристических механизмов бюджетирования к механизмам на основе количественного моделирования социальноэкономических параметров жизнедеятельности.

В рамках концепции предусматривается выделение пяти основных подсистем ее реализации:

1. Систему мотивации, основу которой составляет оценка вклада поколений в развитие муниципалитета «вчера-сегодня-завтра».

2. Систему инициирующих событий (поводов) для стимулирования гражданской активности, таких как день основания города (района), юбилей выдающихся земляков, периодические конкурсы и форумы различного масштаба и т.д.

3. Институциональную основу, под которой могут пониматься: территориальное общественное самоуправление (ТОC), корпорации развития местных сообществ (КРМС), общественные инновационно-образовательные парки (ИОП) и т.д.

4. Систему организационно-методического сопровождения, под которой понимается совокупность научно обоснованных форм и механизмов поддержки, а также необходимой информационно-аналитической инфраструктуры.

5. Систему оценки конечных и промежуточных результатов, ориентированную на рост гражданской активности, эффективности муниципального управления и повышение собираемости платежей за жилищно-коммунальные услуги.

Предварительные расчет использования социальных инициатив показали возможность повышения темпов роста экономики региона до $30 \%$ от прогнозируемого в настоящее время уровня.

Реализация концепции сбалансированных социальных инициатив планируется осуществить в несколько этапов:

1. Изучить с позиции социальных инициатив мировой опыт партисипаторного бюджетирования: особенности, условия внедрения, эффективность.

2. Проанализировать результаты апробирования вариантов и элементов партисипаторного бюджетирования в Республике Башкортостан и Российской Федерации в 2014-2015 гг.

3. Разработать концепцию социальных инициатив на основе отечественной модели партисипаторного бюджетирования (с учетом параметров развития муниципальных образований).

4. Разработать программу формирования и внедрения партисипаторного бюджетирования для муниципальных образований Республики Башкортостан.

5. Организовать центр научно-практического анализа и внедрения методических основ разработки и реализации партисипаторного бюджетирования в Республике Башкортостан.

Таким образом, по мнению авторов, в России имеется в достаточной мере интеллектуальный и научный потенциал в сфере экономики и управления, что создает предпосылки для использования оперативного, но отличного от пройденного зарубежными 
странами, пути разработки и реализации программ партисипаторного бюджетирования в условиях нестабильной рыночной среды.

\section{ЛИТЕРАТУРА}

1. Бублик Н.Д., Чувилин Д.В. Направления совершенствования системы управления жилищно-коммунального хозяйства муниципалитета на основе развития принципов самоорганизации // Интернет-журнал «Науковедение». 2014. №6. URL: http://naukovedenie.ru/PDF/04EVN614.pdf (дата обращения: 10.08.2016).

2. Бублик Н.Д., Лукина И.И., Фазлутдинов Р.А., Чувилин Д.В. Процедуры партисипаторного бюджетирования как основополагающего элемента концепции сбалансированных инициатив местных сообществ // Интернет журнал «Науковедение». $2016 . \quad$ №4. URL: http://naukovedenie.ru/PDF/62EVN416.pdf (дата обращения: 10.08.2016).

3. Вагин В.В., Шаповалова Н.А., Гаврилова Н.В. Инициативное бюджетирование: международный контекст российской версии // Научно-исследовательский финансовый институт. Финансовый журнал. 2015. №3.

4. Вагин В.В., Шаповалова Н.А., Гаврилова Н.В. Инициативное бюджетирование в России: лучшие практики и направления развития // Научно-исследовательский финансовый институт. Финансовый журнал. 2015. №4.

5. Вагин В.В. Инициативное бюджетирование в Российской Федерации: основные особенности и результаты // Научно-исследовательский финансовый институт. Финансовый журнал. 2015. №5.

6. Первый семинар «Бюджет как предмет социальных наук» // Научноисследовательский финансовый институт. Финансовый журнал. 2015. №2.

7. Вагин В.В., Шаповалова Н.А., Гаврилова Н.В.. Анализ и систематизация лучшей российской и зарубежной практики вовлечения граждан в бюджетные инициативы [Электронный ресурс] // Материалы Всероссийской конференции по инициативному бюджетированию. Москва, 2015. 215 с. Режим доступа: http://www.nifi.ru/images/FILES/NEWS/21-221015_PB_conf/info_1.pdf.

8. Шилов Л.А., Димке Д.В.., Гребенщикова Т.Ю. Проекты партисипаторного бюджетирования Комитета гражданских инициатив и Европейского университета в Санкт-Петербурге [Электронный ресурс] // Материалы Всероссийской конференции по инициативному бюджетированию. Москва, 2015. 215 с. Режим доступа: http://www.nifi.ru/images/FILES/NEWS/21221015_PB_conf/info_1.pdf.

9. Шульга И.Е., Сухова А., Хачатрян Г. Программа поддержки местных инициатив: совершенствование местного самоуправления и развитие инициативного бюджетирования [Электронный ресурс] // Материалы Всероссийской конференции по инициативному бюджетированию. Москва, 2015. 215 с. Режим доступа: http://www.nifi.ru/images/FILES/NEWS/21221015_PB_conf/info_1.pdf.

10. McNulty S. Improved Governance? Exploring the Results of Peru's Participatory Budgeting Process // Annual Meeting of the American Political Science Association, August 29-September 1, 2013. 14 p.

11. Sintomer Y., Herzberg C., Allegretti G., Röcke A. and Alves M. Participatory Budgeting Worldwide - Updated Version. Bonn: ENGAGEMENT GLOBAL gGmbH November 2013. 96 p.

12. Masser K. Participatory budgeting as its critics see it. Режим доступа: http://www.buergerhaushalt.org/en/article/participatory-budgeting-its-critics-see-it. 


\title{
Bublik Nikolay Dmitrievich \\ Financial university under the government of the Russian Federation \\ Ufa branch, Russia, Ufa \\ E-mail: Bnd-ufa@bk.ru \\ Lukina Irina Ivanovna \\ Financial university under the government of the Russian Federation \\ Ufa branch, Russia, Ufa \\ E-mail: Irina-ufa@bk.ru
}

Fazlutdinov Rustam Anfirovich

Office of the government of the Republic of Bashkortostan, Russia, Ufa

E-mail: Fazlutdinov.r@bashkortostan.ru

Chuvilin Denis Valerjevich

Financial university under the government of the Russian Federation

Ufa branch, Russia, Ufa

E-mail: DVChuvilin@fa.ru

\section{Prerequisites for formation of the balanced initiatives concept based on adaptation of participatory budgeting to Russian conditions}

\begin{abstract}
The article presents the results of a study of world and national practice of a participatory budgeting carried out by systematizing the publications of domestic and foreign scholars and practitioners. It was revealed that main part of studies is dedicated to the socio-political component of participatory budgeting processes. At the same time there are a several trends after 25 years the use of a participatory budgeting, including: increasing in the scale; growing the variety of forms and mechanisms; presence of conflicting factors, which lead to the appearance of negative effects and dissatisfactions by the results of joint work in the medium term.

The hypothesis about dependence of the participatory budgeting development from the level of knowledge and competence of the population was proposed in the article. Direct interrelation between the level of education and the extent of a participatory budgeting was found by analysis of statistical data for 40 countries. In this connection, the necessity of formation of national model in participatory budgeting was confirmed. However, the current domestic practices of participatory budgeting are largely based on international experience. There is a significant shift toward supporting local initiatives to address acute but single problems of communities.

In the article the author's approach to determining the place of a participatory budgeting in civil activity on the basis four perspectives of the BSC was offered. It was determined that participatory budgeting as an element of the financial perspective characterizes the final result of social processes associated with the formation of the value estimation and value proportions. Thus, it is assumed that efficiency of participatory budgeting is largely determined by the level of development other forms of self-organization. In this regard, evolutionary «spiral» was proposed to show the logic of synergy effects formation and the sequence of development the social selforganization forms. The principal aspects taking into account Russian conditions were formulated for development national model in participatory budgeting within the framework of the balanced initiatives concept: the rejection of the socio-political assessments in favor of a comprehensive evaluation based on value-oriented approach; use BSC mechanisms to select the best initiatives; shift from expert-heuristic mechanisms of budgeting to mechanisms based on quantitative modeling of
\end{abstract}


socio-economic parameters. he elements of the balanced initiatives concept and the main stages of its implementation in the Republic of Bashkortostan were determined in the article.

Keywords: participatory budgeting; initiative budgeting; budget of development; local communities; balanced initiatives; Balanced Scorecard (BSC); budgeting procedures; budget distribution; municipal investments; projects of development

\section{REFERENCES}

1. Bublik N.D., Chuvilin D. Directions of improving the management system of municipal housing and communal services on the basis of the principles of selforganization of the population // Internet magazine "Science of science." 2014. №6. URL: http://naukovedenie.ru/PDF/04EVN614.pdf (reference date: 10.08.2016).

2. Bublik N.D., Lukin I.I., Fazlutdinov R.A., Chuvilin D.V. The procedures of participatory budgeting as a fundamental element of a balanced community's initiatives concept // Internet - journal "Science of science." 2016. №4. URL: http://naukovedenie.ru/PDF/62EVN416.pdf (reference date: 10.08.2016).

3. Vagin V.V., Shapovalov N.A., Gavrilov N.V. Proactive Budgeting: international context // Russian version of the Research Institute of Finance. Financial magazine. 2015. №3.

4. Vagin V.V., Shapovalov N.A., Gavrilov N.V. Proactive Budgeting in Russia: best practices and directions of development // Scientific-Research Institute of Finance. Financial magazine. 2015. №4.

5. Vagin V.V. Proactive Budgeting in the Russian Federation: main features and results // Research Institute of Finance. Financial magazine. 2015. №5.

6. The first seminar "Budget as a subject of social sciences" // Scientific-Research Institute of Finance. Financial magazine. 2015. №2.

7. Vagin V.V., Shapovalov N.A., Gavrilova N. Analysis and systematization of the best Russian and foreign practice of involving citizens in the budget initiatives [Electronic resource] // Proceedings of the All-Russian Conference on proactive budgeting. Moscow, 2015. 215 pp. Access: http://www.nifi.ru/images/FILES/NEWS/21221015_PB_conf/info_1.pdf.

8. Shilov L.A., Dimka D.V., Grebenshchikov T.Y. Projects a participatory budgeting of the Committee of Civil Initiatives and the European University in St. Petersburg [Electronic resource] // Proceedings of the All-Russian Conference on proactive budgeting. $\quad$ Moscow, $2015 . \quad 215$ pp. Access: http://www.nifi.ru/images/FILES/NEWS/21-221015_PB_conf/info_1.pdf.

9. Shulga I.E., Sukhov A., Khachatryan G. Program of supporting local initiatives: the improvement of local government budgeting and proactive development [electronic resource] // Proceedings of the All-Russian Conference on proactive budgeting. Moscow, 2015. 215 pp. Access: http://www.nifi.ru/images/FILES/NEWS/21221015_PB_conf/info_1.pdf.

10. McNulty S. Improved Governance? Exploring the Results of Peru's Participatory Budgeting Process // Annual Meeting of the American Political Science Association, August 29-September 1, 2013. 14 p.

11. Sintomer Y., Herzberg C., Allegretti G., Röcke A. and Alves M. Participatory Budgeting Worldwide - Updated Version. Bonn: ENGAGEMENT GLOBAL gGmbH November 2013. 96 p.

12. Masser K. Participatory budgeting as its critics see it. Access: http://www.buergerhaushalt.org/en/article/participatory-budgeting-its-critics-see-it. 